\title{
Andrographolide impedes cancer stemness and enhances radio-sensitivity in oral carcinomas via miR-218 activation
}

\author{
Po-Yu Yang ${ }^{1,2,4, *}$, Pei-Ling Hsieh ${ }^{3, *}$, Tong Hong Wang ${ }^{5,6,7, *}$, Cheng-Chia Yu $\mathbf{u}^{1,2,3,4, *}$, \\ Ming-Yi Lu ${ }^{1,2,3,4}$, Yi-Wen Liao ${ }^{1}$, Tzu-Hsin Lee ${ }^{1,2}$, Chih-Yu Peng ${ }^{1,2,3,4}$ \\ ${ }^{1}$ School of Dentistry, Chung Shan Medical University, Taichung, Taiwan \\ ${ }^{2}$ Department of Dentistry, Chung Shan Medical University Hospital, Taichung, Taiwan \\ ${ }^{3}$ Institute of Oral Sciences, Chung Shan Medical University, Taichung, Taiwan \\ ${ }^{4}$ Oral Medicine Center, Chung Shan Medical University, Taichung, Taiwan \\ ${ }^{5}$ Tissue Bank, Chang Gung Memorial Hospital, Tao-Yuan, Taiwan \\ ${ }^{6}$ Research Center for Industry of Human Ecology, Chang Gung University of Science and Technology, Tao-Yuan, Taiwan \\ ${ }^{7}$ Graduate Institute of Health Industry Technology, Chang Gung University of Science and Technology, Tao-Yuan, Taiwan \\ *These authors contributed equally to this work
}

Correspondence to: Chih-Yu Peng, email: cyp@csmu.edu.tw

Keywords: oral squamous cell carcinomas, andrographolide, miR-218, cancer stemness

Received: October 31, $2016 \quad$ Accepted: November 23, $2016 \quad$ Published: December 01,2016

\section{ABSTRACT}

Current evidence suggests that oral cancer stem cells (OCSCs) possess high tumorigenic and metastatic properties as well as chemo- and radioresistance. In this study, we demonstrated that andrographolide, the main bioactive component in the medicinal plant Andrographis, significantly reduced oncogenicity and restored radio-sensitivity of $\mathrm{ALDH1}^{+} \mathrm{CD}_{44}{ }^{+}$OCSCs. Mechanistic studies showed that andrographolide treatment increased the expression of microRNA-218 (miR-218), leading to the downregulation of Bmi1. We showed that knockdown of miR-218 in ALDH1CD44 non-OCSCs enhanced cancer stemness, while silencing of Bmi1 significantly counteracted it. Furthermore, we found tumor growth was reduced in mice bearing xenograft tumors after andrographolide treatment via activation of miR-218/Bmi1 axis. Together, these data demonstrated that the inhibition of tumor aggressiveness in OCSCs by andrographolide was mediated through the upregulation of $\mathbf{m i R - 2 1 8}$, thereby reducing Bmi1 expression. These findings suggest that andrographolide may be a valuable natural compound for anti-CSCs treatment of OscC.

\section{INTRODUCTION}

Oral squamous cell carcinomas (OSCC) ranks as the sixth most common cancer with high incidence and represents a significant contributor to burden of cancer globally [1]. Unfortunately, treatments including extensive surgery, radiotherapy, chemotherapy or concurrent chemo/ radiation are not effective for patients with advanced OSCC due to tumor recurrence, metastasis, or poor response to chemo/ radiotherapy [1]. It has been indicated that cervical lymph node metastasis is the major cause of death in OSCC patients [1]. As such, it is necessary to identify effective therapies for these patients and understand the molecular mechanisms underlying lymph node metastasis. Given that cancer stem cells (CSCs) have been considered to be responsible for metastasis and resistance to chemo/radiotherapy in OSCC [2-4], CSCs-targeted therapy may be a useful strategy against OSCC. Our previous study has shown that OSCC-CSCs were highly tumorigenic, metastatic, resistant to radio/chemotherapy and had increased expression of epithelial-mesenchymal transition (EMT) markers [3]. Other recent reports revealed that CD44 [5], CD133 [6], aldehyde dehydrogenase (ALDH) [7], membrane GRP78 [8], side population [9] and c-Met [10] could be used to detect CSCs from OSCC as well.

Andrographis paniculata (Burm. f) Ness is an herbal plant in the Acanthaceae family. It is widely 
cultivated in India, Thailand and China and has been used as a traditional medicine to treat various diseases [11]. The most abundant diterpene lactone in the leaves and stem is called andrographolide and it exhibits numerous bioactive properties, including anti-cancer [12], anti-inflammation [13], hepatoprotection [14] and anti-infection [15]. Several studies have demonstrated its anti-cancer potential and possible mechanisms. It has been reported that andrographolide reduces invasiveness of human non-small cell lung cancer A549 cells by inhibiting MMP-7 expression through downregulation of $\mathrm{PI} 3 \mathrm{~K} /$ Akt signaling pathway [16]. It is able to cause cell growth suppression of human colorectal carcinoma LoVo cells by promoting cell-cycle arrest at $\mathrm{G}_{1} / \mathrm{S}$ phase and increasing the expression of p53, p21 and p16 [17]. And it has been shown to inhibit NF- $\mathrm{kB}$-induced bcl-2 activation and modulate $\mathrm{p} 53$-mediated caspase-3 gene expression, thereby increasing apoptosis of B16F-10 melanoma cells [18]. Andrographolide is also a potent inhibitor for multiple myeloma [19] and melanoma CSCs [20]. Nevertheless, efficacy of using andrographolide in the specific subset of OCSCs still remains to be determined.

MicroRNAs (miRNAs), a class of small noncoding RNAs regulating the gene expression at the posttranscriptional level by binding to target mRNAs within the 3' untranslated region (UTR), have been found to be involved in many important biological processes [21-23]. In particular, it has been found that miR-218 acts as a tumor suppressor by targeting many oncogenes related to proliferation [24], apoptosis [25] and invasion [26]. miR-218 is a vertebrate-specific intronic miRNA coexpressed with its host genes, tumor suppressor gene SLIT2/3. The mature form of miR-218 is generated from two separate loci, miR-218-1 and miR-218-2, which are located on chromosomes $4 \mathrm{p} 15.31$ and $5 \mathrm{q} 35.1$ within the introns of SLIT2 and SLIT3, respectively [27]. Several studies have shown that miR-218 is significantly downregulated in colorectal cancer [28], breast cancer [29], clear cell renal cell carcinoma [30], supporting miR218 as a key factor in human tumorigenesis. Also, it has been linked to the regulation of cancer stemness. For example, miR-218 attenuates self-renewal in glioma stemlike cells [31]. Most importantly, previous study showed that miR-218 expression is significantly upregulated by Andro pretreatment in human alveolar epithelial A549 cells with reduced inflammatory response and oxidative stress [32]. Consequently, it is imperative to elucidate the relationship between Andro and miR-218 in eliciting antiOSCC activity.

In the current study, we evaluated the effect of andrographolide on cell survival, self-renewal, expression of cancer stem cell markers in vitro and tumorigenecity in vivo. We also found administration of andrographolide enhanced the tumor sensitization to radiation therapy. In addition, our results indicated that miR-218 may play a pivotal role in the anti-CSCs property of andrographolide by targeting Bmi1. Overall, we demonstrated the tumor suppressive activity of andrographolide in OCSC and provided evidence for downstream mechanisms involved in this anti-cancer response.

\section{RESULTS}

\section{Andrographolide reduces cell proliferation and self-renewal in oral cancer stem cells (OCSCs)}

$\mathrm{ALDH} 11^{+} \mathrm{CD} 44^{+}$OCSCs were isolated from patientderived cell lines and used to study the CSC properties, since ALDH1 and CD44 have been recognized as markers to distinguish malignant from premalignant cells as well as identify the putative OCSCs $[33,34]$. We first investigated the cell survival of these two $\mathrm{ALDH} 1^{+} \mathrm{CD} 44^{+}$ OCSCs and normal human oral keratinocytes (NHOK) in order to understand the cytotoxicity of Andrographolide (Figure 1A). As shown in Figure 1B, andrographolide markedly suppressed the viability of two OCSCs in a dose-dependent manner using MTT assay.

Successful sphere formation following serial passages of culture is one of the characteristics to access the capacity of persistent self-renewal in CSCs [35]. Therefore, we evaluated the secondary sphere-forming ability of OCSCs after andrographolide treatment. Our result demonstrated that andrographolide exhibited a strong anti-sphere forming potential in a dose-dependent fashion (Figure 1C) and effectively inhibited their capacity of self-renewal in OCSCs.

\section{Andrographolide represses ALDH1 activity and the expression of stemness signatures in OCSCs}

ALDH1 enzymatic activity was detected by ALDEFLUOR assay and our data suggested administration of andrographolide significantly resulted in a concentration-dependent decrease in ALDH1 activity of both OCSCs (Figure 2A). Andrographolide treatment also suppressed the percentages of CD44+ cells (Figure 2B). To further determine whether the reduction in CSCs hallmarks following andrographolide treatment was associated with the expression of stemness-related markers, the levels of Oct-4, Nanog and Sox 2 in OCSCs were analyzed by real-time PCR and western blot. The expression of mRNA (Figure 2C) and protein (Figure 2D) levels of Oct-4, Nanog, and Sox 2 in both OCSCs were significantly reduced.

\section{Inhibition of oncogenicity and enhanced radio-sensitivity in OCSCs by Andrographolide}

Since CSCs appear to play a critical role in tumorigenesis and metastasis [36], it is extremely important to assess oncogenicity of OCSCs when testing the efficacy of andrographolide. Overall, a dose-dependent 
suppression of tumor-initiating activity including migration (Figure 3A), invasion (Figure 3B), and colony formation (Figure 3C) was observed. There results clearly demonstrated that andrographolide exerted a pronounced oncogenic-inhibitory effect.

Reemergence of radiotherapy-resistant CSCs is considered to be responsible for the recurrence of cancers after conventional therapeutic treatments [37]. As expected, OCSCs were more radio-resistant compared with the parental OSCC using cell viability assay. Nevertheless, the sensitivity to radiation therapy in OCSCs was dramatically improved in combination with andrographolide (Figure 4A). We also observed an enhanced antitumor activity via the synergic action of andrographolide and radiation in invasion (Figure 4B) and colony-forming potentials (Figure 4C) of OCSCs.

\section{Andrographolide increases the expression of tumor suppressive miR-218}

Numerous studies have implicated miRNAs involve in the regulation of CSCs properties [38-40]. In the current study, we found delivery of andrographolide caused a dose-dependent increase in the level of miR-218 expression using real-time RT-PCR analysis (Figure 5A). Following identification of Bmil as the potential target of miR-218 through Target Scan program, we constructed reporter plasmids containing either full-length or mutated forms of the 3'UTR region of Bmil (Figure 5B). Luciferase reporter assay showed that miR-218 decreased the luciferase activity of reporter plasmids containing full-length Bmil 3'UTR and this phenomenon was not observed in mutant form
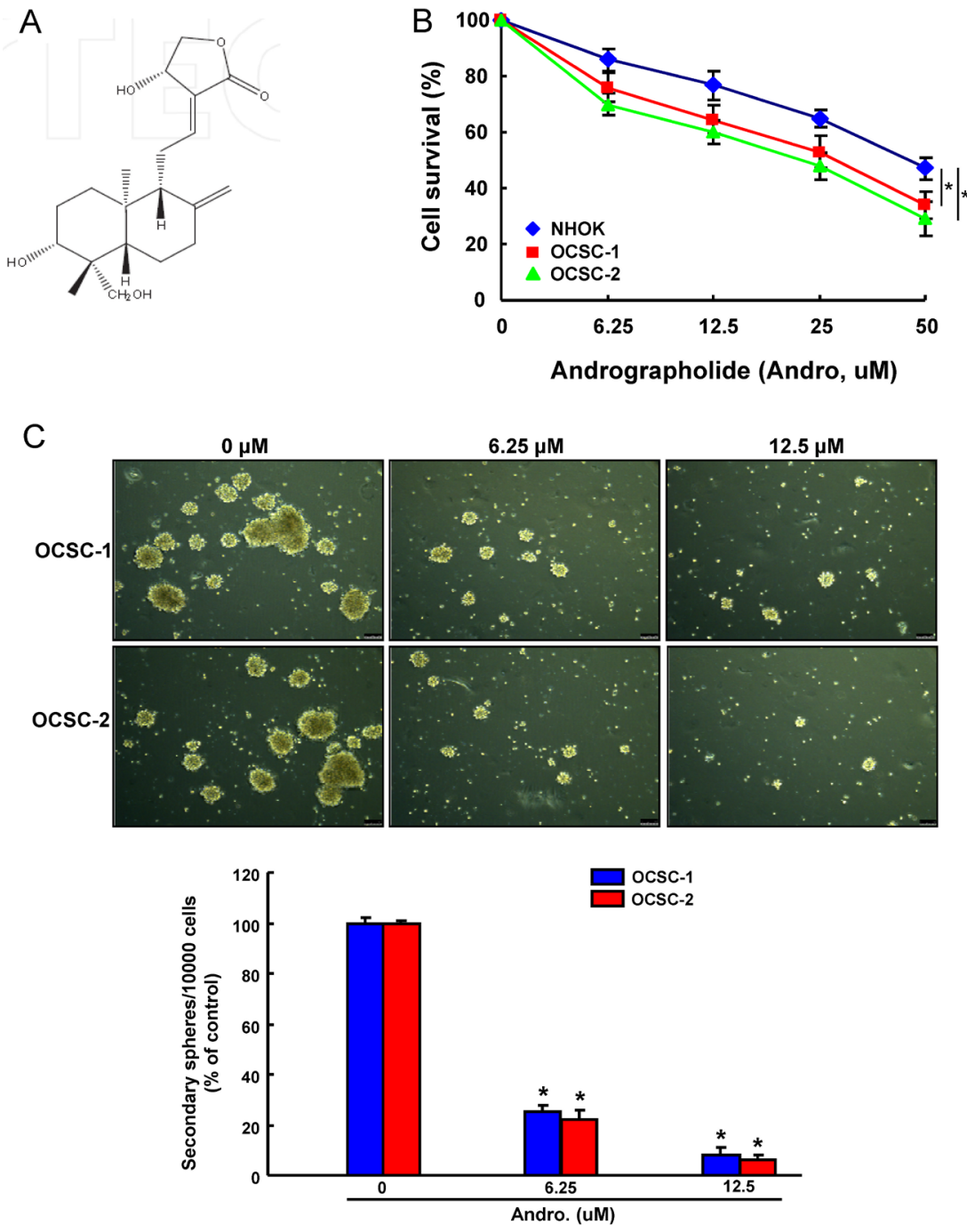

Figure 1: The cytotoxicity and effect of andrographolide on OCSCs self-renewal property (A)The chemical structure of andrographolide; (B) NHOK cells and two $\mathrm{ALDH}^{+} \mathrm{CD} 44^{+}$OCSCs from primary cultivated OSCC were treated with various concentrations of andrographolide for $24 \mathrm{hr}$ followed by MTT assay; (C) OCSCs treated with or without andrographolide were subjected to a secondary sphere-forming assay. The number of spheres was calculated and data was presented as percentage of control. Experiments were performed in triplicate. Values are expressed as mean $\pm \mathrm{SD}$. ${ }^{*} p<.05$ compared to control. 
(Figure 5C), confirming Bmil as a target of miR-218 in OCSCs. Furthermore, we exogenously overexpressed miR-218 in OCSCs and the efficiency was validated by real-time RT-PCR analysis (Figure 5D). In accordance with the previous finding, the protein level of Bmil was decreased in the miR-218-overexpressing OCSCs (Figure 5E). Most importantly, overexpression of miR-218 significantly suppressed the radio-resistance (Figure 5F). Overexpression of miR-218 significantly suppressed self-renewal ability (Supplementary Figure S1A) and nvasion capacity (Supplementary Figure S1B) in OCSCs.

\section{miR-218 suppresses cancer stemness and invasiveness by targeting Bmi1}

The role of Bmil in the miR-218-mediated inhibition of cancer stemness was further clarified. First, the elevated expression of Bmi1 in non-CSCs treated with miR-218 knockdown sponge (Spg-miR-218) was verified by western blotting (Figure 6A). We showed that silencing of endogenous miR-218 induced sphere-forming capability in non-CSCs, which was abolished by knockdown of
Bmil (Figure 6B). Also, wound-healing (Figure 6C) and invasion (Figure 6D) abilities were increased in Spg-miR-218-treated non-CSCs, and silencing of Bmi1 counteracted these responses (Figure 6C-6D). Taken together, these results demonstrated that miR-218-induced downregulation of Bmil suppressed self-renewal, tumor cell motility and invasion in OSCC cells.

\section{Administration of andrographolide exerts an inhibitory effect on tumor growth in vivo through miR-218 activation}

To validate the efficacy of andrographolide-mediated anti-tumorigenic function in vivo, immunocompromised mice bearing OCSC xenografts received andrographolide treatment or vehicle (water) by oral gavage. We found that tumor formation was significantly suppressed following administration of andrographolide by day 20 compared to vehicle group (Figure 7A). The upregulation of miR-218 (Figure 7B) and downregulation of Bmil (Figure 7C) were confirmed by real-time RT-PCR and western blotting analysis, respectively.
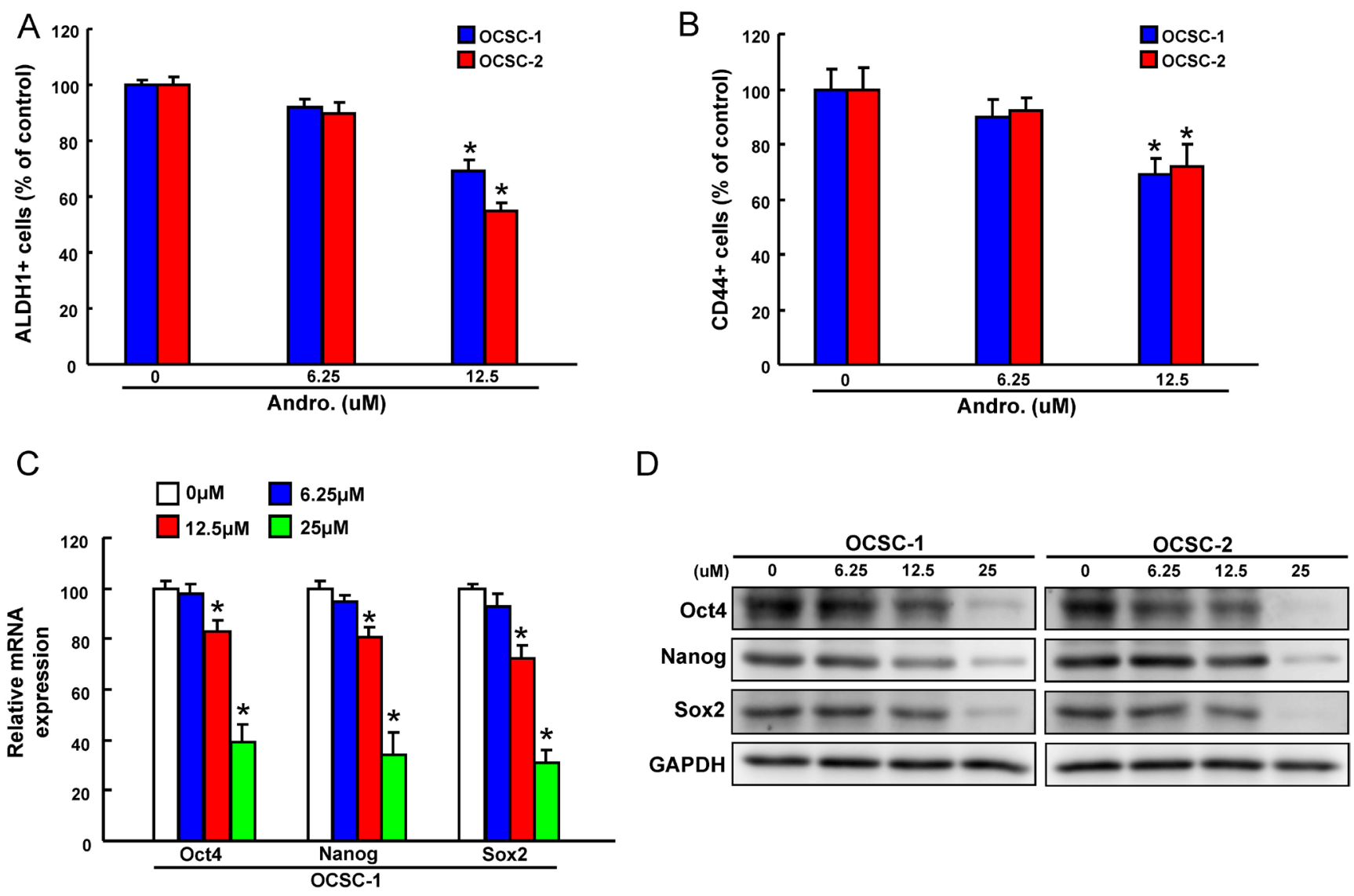

Figure 2: The effect of andrographolide on cancer stemness marker expression (A)The ALDH1 activity and (B) CD44 positivity of OCSCs treated with or without andrographolide was assessed by flow cytometry and data was presented as percentage of control; (B) mRNA and (C) protein expressions of the stemness markers (Oct4, Nanog, and Sox2) in andrographolide-treated OCSCs. Experiments were performed in triplicate. Values are expressed as mean $\pm \mathrm{SD}$. ${ }^{*} p<.05$ compared to control. 


\section{DISCUSSION}

Metastasis is the main reason for the high mortality of cancer and cervical lymph node metastasis has been considered to be the most important adverse prognostic factor and major cause of death for OSCC patients [1]. Among various factors regulating metastasis properties, miR-218 has been recently identified as a metastasis suppressor. It was found that miR-218 was dramatically downregulated in metastatic prostate [41] and cervical cancer cells [32]. Overexpression of miR-218 was shown to inhibit lung cancer metastasis in tumor bearing mice $[32,42]$. Additionally, several studies have reported that suppression of miR-218 resulted in increased invasive ability of gastric cancer [43], glioma [44] or pancreatic ductal adenocarcinoma cells [45], whereas restoration of miR-218 led to significant inhibition of cell migration and invasion in OSCC [46], cervical squamous cell carcinoma
[42] and renal carcinoma cells [47]. Consistent with the previous studies, we showed knockdown of miR-218 expression in non-CSCs induced self-renewal, tumor cell motility and invasion in OSCC, while knockdown of Bmil effectively reversed these phenomena (Figure 5). To our knowledge, this is the first report demonstrating miR-218 expression is crucial for maintaining metastasis of OSCC via targeting Bmil.

B-cell-specific Moloney murine leukemia virus integration site 1 (Bmil) is a member of polycomb repressive complex 1 , and it has been implicated as one of the important regulators of self-renewal in stem cells $[48,49]$. On other hand, epithelial-mesenchymal transition (EMT), a critical process involved in the transdifferentiation of polarized epithelial cells into an invasive mesenchymal phenotype, has emerged as an essential driver of malignant transformation including tumorigenicity, metastasis and cancer stemness [50].
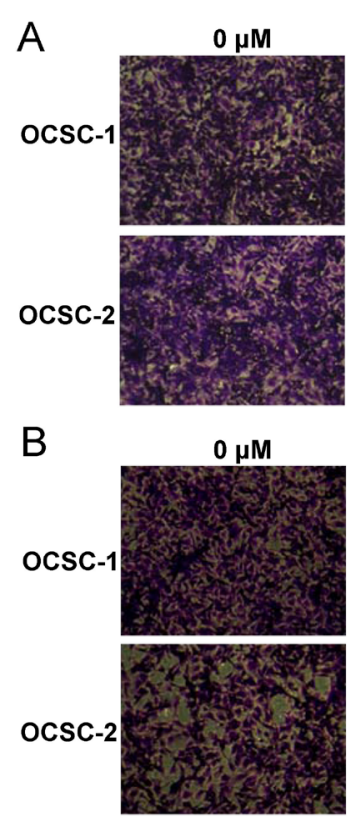

C

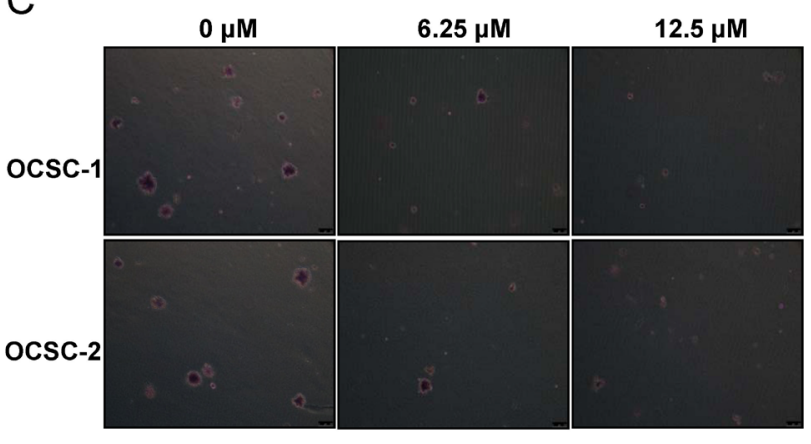

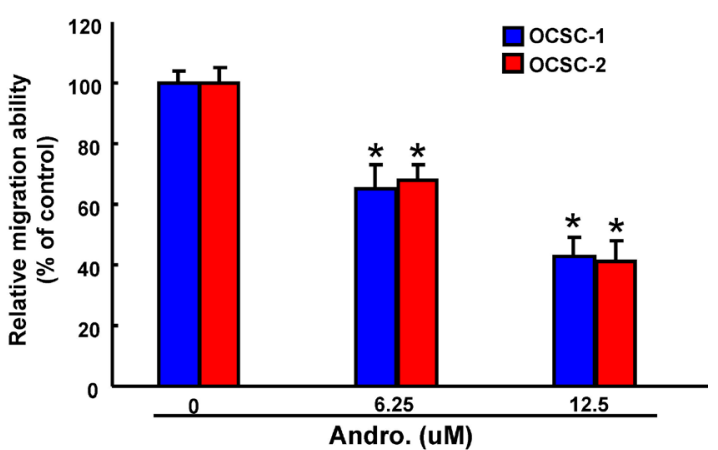
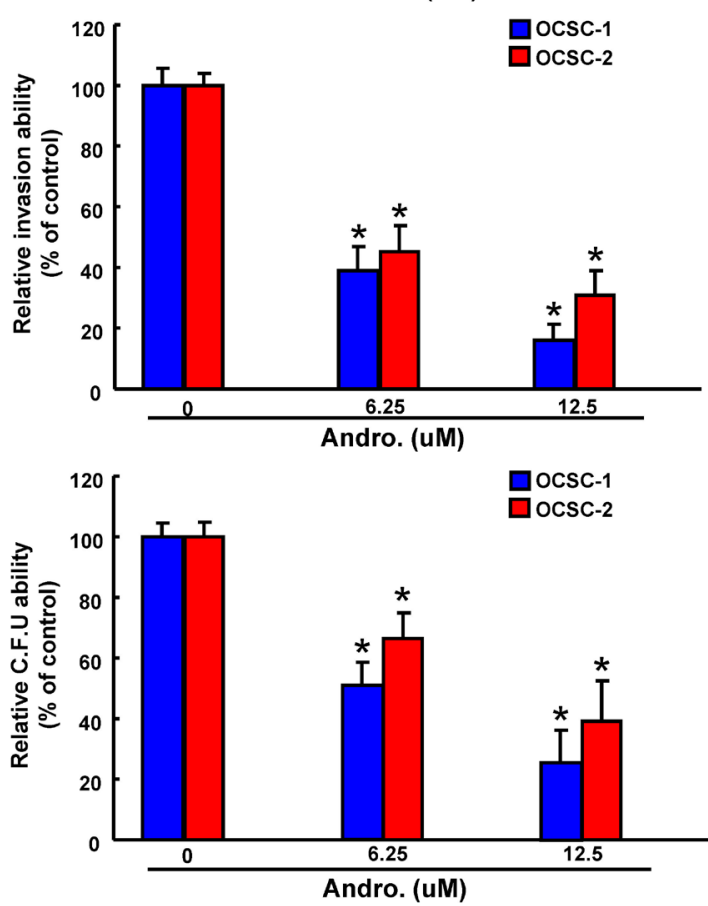

Figure 3: Anti-oncogenic effect of andrographolide in OCSCs Representative images (left) and quantification (right) of (A) migration assay, (B) Matrigel invasion assay and (C) soft agar colony formation assay of OCSCs treated with various concentration of andrographolide. Experiments were performed in triplicate. Values are expressed as mean \pm SD. ${ }^{*} p<.05$ compared to control. 
It has been indicated that Bmil acts synergistically with Twist to promote EMT and tumor-initiating capability in OSCC and the increased expression of Bmil is correlated with unfavourable prognosis [51]. Apart from induction of EMT and cancer cell stemness, growing evidence suggests that tumor recurrence and chemoresistance of CSCs are in part due to the activation of Bmi1 $[52,53]$. Recent studies have revealed that downregulation of Bmil enhanced the sensitivity of chemotherapeutic drugs in various carcinomas by regulating oxidative stress and inducing apoptosis [54-56]. In the present study, we demonstrated the role of Bmil in the miR-218-mediated inhibition of cancer stemness and invasiveness. Future research should thoroughly explore the miR-218/Bmil axis in regulation of EMT in OSCC.

OSCC is often associated with high incidence of tumor recurrences, which account for the majority of treatment failures post-surgery or conventional radiotherapy. Cancer recurrence is partly attributable to radioresistance and represents a major clinical challenge. In order to obtain a better therapeutic outcome of malignant OSCC, it is necessary to develop more specific treatment options and effective radiosensitizers. Numerous studies have suggested that andrographolide enhanced radiosensitivity in human ovarian cancer SKOV3 xenografts [57] and esophageal cancer cells [58] through apoptosis induction as well as Ras-transformed cells to radiation both in vitro and in vivo [59]. In associated with these studies, we also found andrographolide combined with radiation displayed synergistic effect on invasiveness and clonogenicity, leading to significantly suppressed tumorigenesis in OCSCs.

In conclusion, our data indicate that andrographolide can inhibit oncogenic properties of OCSCs through activation of miR-218-targeting Bmil. Furthermore, andrographolide has radiosensitizing effect and may serve as an adjuvant therapy to reduce the rate of recurrence. These findings provide a strong rationale for the potential use of andrographolide as a radiosensitizer and anti-CSCs agent.

\section{MATERIALS AND METHODS}

\section{Reagents}

Andrographolide was purchased from Sigma-Aldrich Chemical Co. (St. Louis, MO, USA) and dissolved in DMSO (Merck, Darmstadt, Germany) to obtain a stock
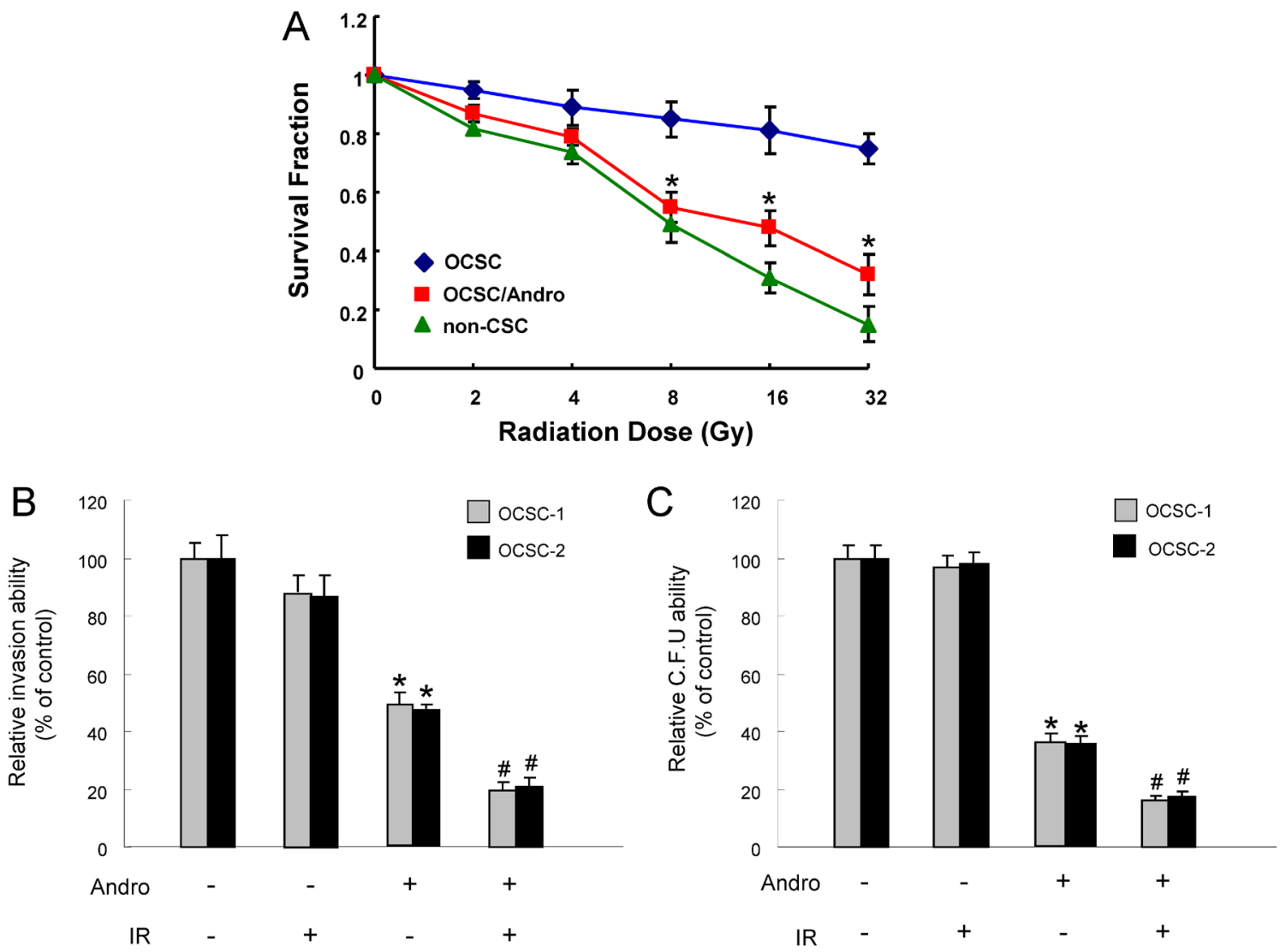

Figure 4: The effect of andrographolide on radio-sensitivity of OCSC (A)The surviving fractions of cancer cells or andrographolide-treated OCSCs were evaluated after various doses of radiation exposure; (B) Invasion and (C) colony-forming ability in OCSCs were examined after treatment with either andrographolide/radiotherapy alone or combination of both. ${ }^{*} p<.05$ andrographolide alone vs. control; $\# p<.05$ andrographolide+ IR vs. andrographolide alone. 
solution of $100 \mathrm{mM}$. Andrographolide was further diluted in culture medium to the appropriate final concentrations prior to use.

\section{Isolation of oral cancer stem cells}

All procedures of tissue acquirements were approved by Institutional Review Committee at Chung Shan Medical University. Primary oral cancer cell cultures were established as previously described $[60,61]$. To identify $\mathrm{ALDH} 1^{+} \mathrm{CD} 44^{+}$oral cancer stem cells, we stained cells with ALDEFLUOR assay kit (StemCell Technologies, Vancouver, BC, Canada) and anti-CD44 antibody conjugated to phycoerythrin (Miltenyi Biotech., Auburn, CA, USA) followed by fluorescence-activated cell sorting using FACSAria II cell sorter (BD Biosciences, San Jose, CA, USA).

\section{MTT assay}

Cells were incubated with different concentration of andrographolide-containing medium or vehicle $(0.1 \% \mathrm{DMSO})$ at $37^{\circ} \mathrm{C}$ for $24 \mathrm{hr}$ followed by MTT ((3-(4,5-dimethylthiazol-2-yl)-2,5-diphenyl tetrazolium bromide) treatment for $3 \mathrm{~h}$. The blue formazan crystals of viable cells were dissolved in DMSO and then evaluated spectrophotometrically at $570 \mathrm{~nm}$. DMSO-treated group was set as $100 \%$, and data were presented as percentage of DMSO control.

\section{Tumorsphere-forming assay}

Tumor cells were dissociated and cultured as tumorspheres in modified medium consisting of DMEM/F-12 supplemented with N2 (R\&D Systems,

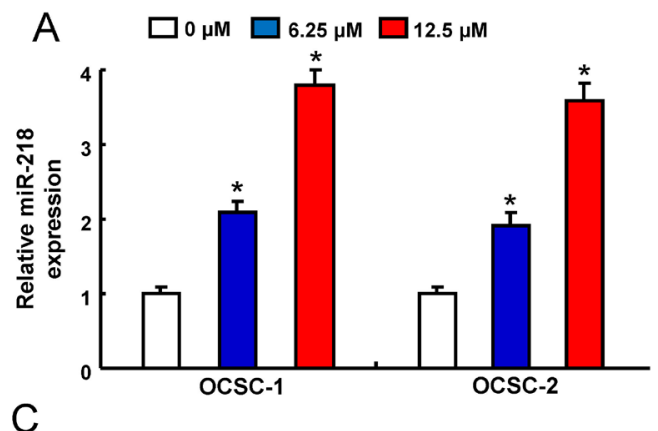

B

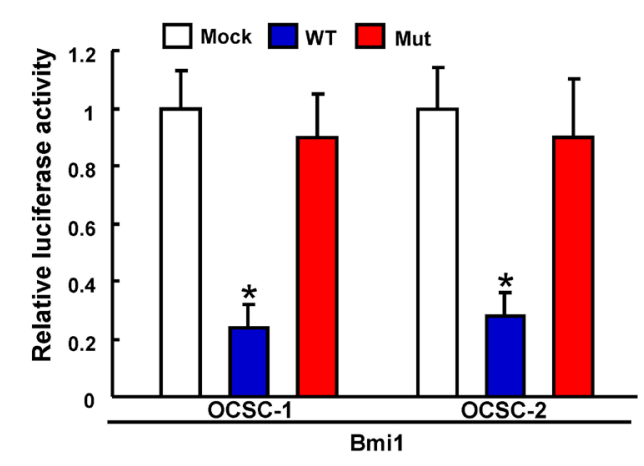

\begin{tabular}{|c|c|c|c|}
\hline Gene & 3'UTR Position & Target Site(s) & \\
\hline Bmi1 & $1470-1477$ & 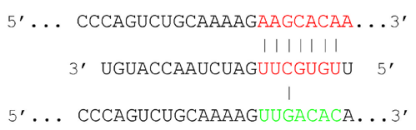 & $\begin{array}{l}\text { (miR-218) } \\
\text { (mutant) }\end{array}$ \\
\hline
\end{tabular}

$E$
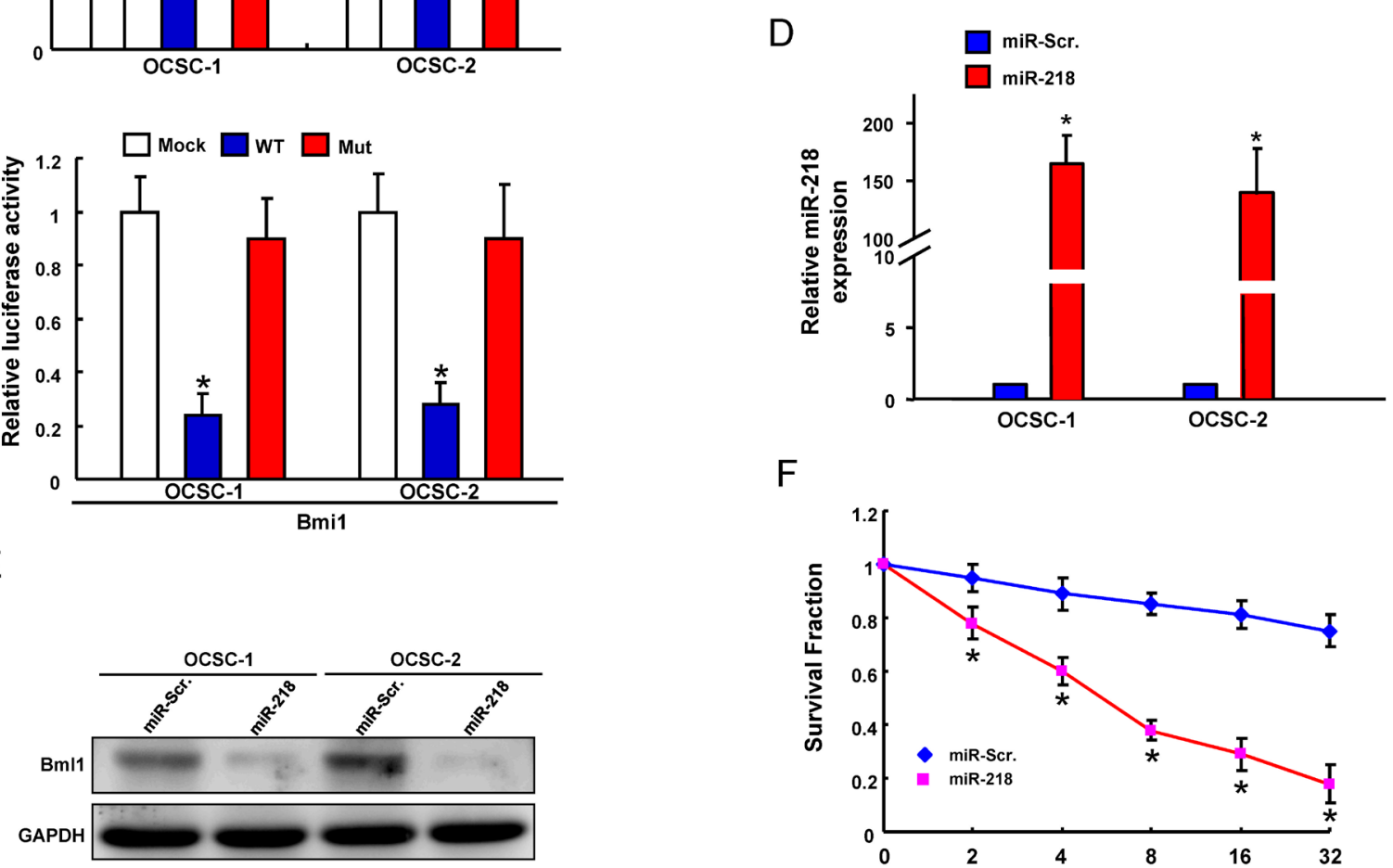

F

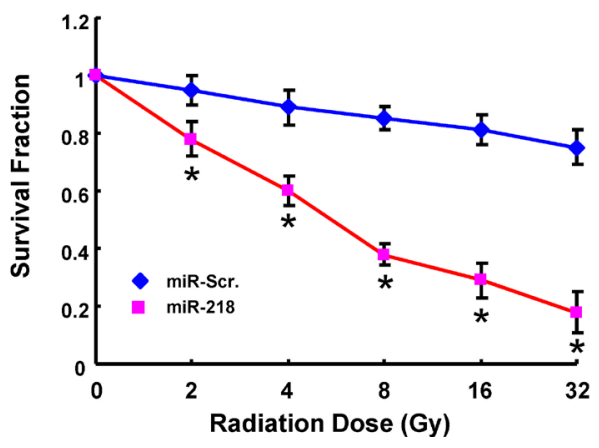

Figure 5: Identification of Bmi18 as a direct target of miR-218 in OCSCs (A) miR-218 expression in andrographolide-treated OCSCs; (B) Schematic representation of the constructed Bmi1 3'UTR reporter plasmids; (C) The wild-type or mutant form of Bmil reporter was co-transfected with miR-218 or empty vector (Mock) into OCSCs. The luciferase activity was assessed and presented as relative units to Mock-treated cells; (D) mRNA expression of miR-218 and (E) protein expression of Bmi1 in OCSCs transfected with pLV-miR-scrambled (pLV-miR-Scr.) or pLV-miR-218; (F) Survival fraction of pLV-miR-Scr or pLV-miR-218-treated OCSCs after various doses of radiation. Experiments were performed in triplicate. Values are expressed as mean \pm SD. ${ }^{*} p<.05$ compared to control. 
A
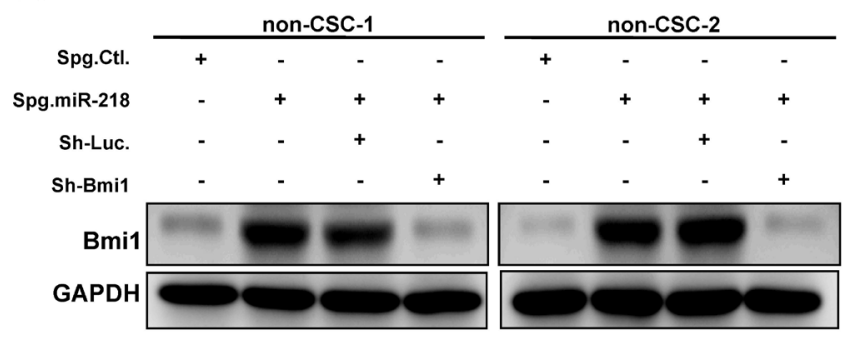

C

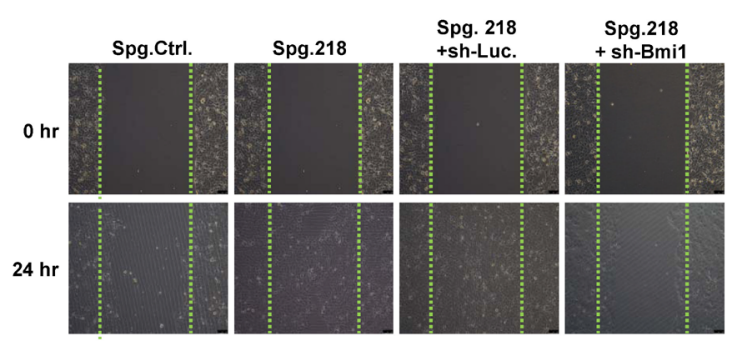

B

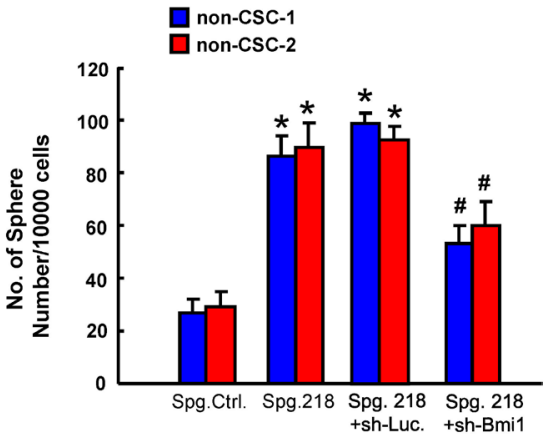

D
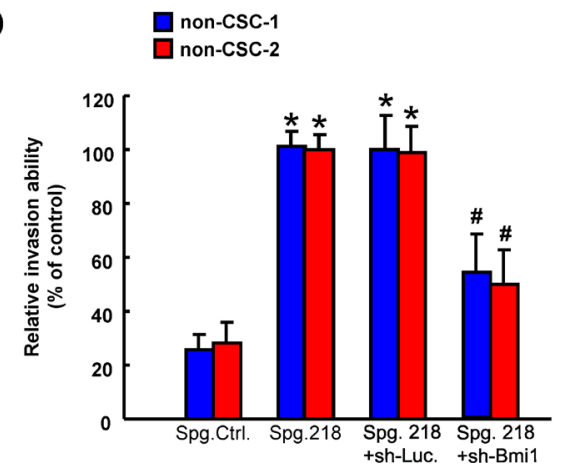

Figure 6: Involvement of Bmi1 in tumor suppressive function of miR-218 (A) Protein expression of Bmi1, (B) sphere formation, (C) wound-healing and (D) invasion ability in ALDH1-CD44- non cancer stem cells (non-CSC) transfected with Spg-Ctl, Spg-miR-218, sh-Luc or sh-Bmi1. Experiments were performed in triplicate. Values are expressed as mean \pm SD. ${ }^{*} p<.05$ compared to Spg.Ctrl.; $\#<.05$ Spg. 218+sh-Bmil compared to Spg. 218+sh-Luc.

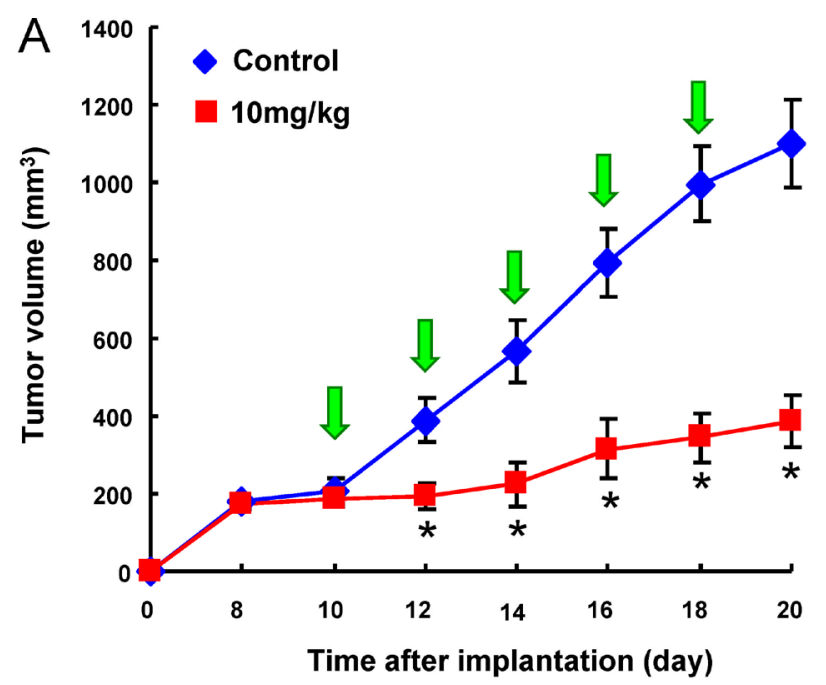

B

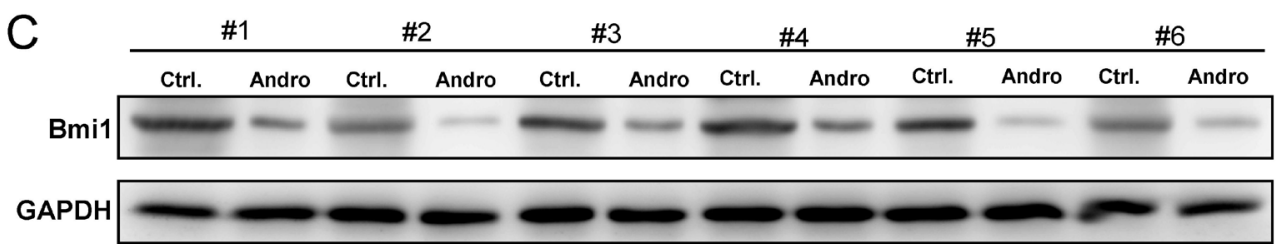

Figure 7: Inhibition of tumor growth by Andrographolide via miR-21/Bmi1 axis (A) Quantification of tumor volume changes following administration of Andrographolide; (B) relative miR-218 expression and (C) Bmil expression in the excised tumors. Experiments were performed in triplicate. Values are expressed as mean $\pm \mathrm{SD}$. ${ }^{*} p<.05$ compared to control. 
Minneapolis, MN, USA), $10 \mathrm{ng} / \mathrm{mL}$ epidermal growth factor (EGF, Invitrogen, Carlsbad, CA, USA), $10 \mathrm{ng} / \mathrm{mL}$ basic fibroblast growth factor (bFGF, Invitrogen), and penicillin/streptomycin at $10^{3}$ live cells per well of ultra-low attachment six-well plate (Corning, NY, USA). Medium was changed every other day for two weeks. The number of tumor spheres formed were observed and counted under a microscope.

\section{ALDH1 activity assay}

ALDH1 activity was examined using ALDEFLUOR assay kit (StemCell Technologies). $5 \times 10^{5}$ cells were suspended in $1 \mathrm{ml}$ ALDEFLUOR assay buffer containing the ALDH substrate and incubated at $37^{\circ} \mathrm{C}$ for 60 minutes. $\mathrm{ALDH}^{+}$cells were analyzed by flow cytometry (FACSCalibur; BD Biosciences) to compare the fluorescence intensity with the DEAB (diethylaminobenzaldehyde)-treated negative control.

\section{Quantitative real-time reverse-transcriptase (RT)-PCR}

Total RNA was extracted from cells or tissues using Trizol reagent (Invitrogen). cDNA synthesis was performed using Superscript III first-strand synthesis system (Invitrogen) according to the manufacturer's instruction. GAPDH housekeeping gene was used as reference. Amplification and detection were carried out on an ABI StepOne ${ }^{\text {TM }}$ Real-Time PCR Systems (Applied Biosystems, Carlsbad, CA, USA) for analysis of stemness-related markers. miR-218 level was quantified by TaqMan miRNA assays with specific primer sets (Applied Biosystems). All reagents and protocols were from Applied Biosystems, and detection was performed using 7900HT fast real-time PCR system.

\section{Western blot}

Cells were lysed in NP-40 buffer and protein concentration was determined using BCA protein assay kit (Thermo Fisher Scientific, Rockford, IL, USA). Samples $(25 \mu \mathrm{g}$ of total protein) were separated by $10 \%$ SDS-PAGE and wet-transferred to a PVDF membrane (Millipore, Billerca, MA, USA). The membrane was incubated with primary antibodies recognizing Oct4 (\#2750, Cell Signaling, Beverly, MA, USA), Nanog (\#3850, Cell Signaling), Sox2 (\#3579, Cell Signaling) or GAPDH (GTX627408, GeneTex, Irvine, CA, USA). Following primary antibodies, the membrane was incubated with corresponding secondary antibodies. The immunoreactive bands were developed using an ECL-plus chemiluminescence substrate (Perkin-Elmer, Waltham, MA, USA) and captured by LAS- 1000 plus Luminescent Image Analyzer (GE Healthcare, Piscataway, NJ, USA).

\section{Migration/invasion assay}

Cell migration and invasion assays were carried out using 24-well plate Transwell $^{\circledR}$ system with a polycarbonate filter membrane of $8-\mu \mathrm{m}$ pore size (Corning). For invasion assay, the membrane was coated with Matrigel. The cells were seeded to the upper compartment at the density of $1 \times 10^{5}$ in $250 \mu \mathrm{L}$ serum-free medium and medium supplemented with $10 \%$ FBS was used as a chemoattractant in the lower chamber. After $24 \mathrm{~h}$ of incubation, the filter membrane was stained with $0.1 \%$ Crystal Violet. The cells were then visualized and counted from five different fields of 100 -fold magnification under an inverted microscope.

\section{Soft agar colony forming assay}

Each well of a six-well culture dish was coated with $1 \mathrm{ml}$ of bottom agar (Sigma-Aldrich) mixture (DMEM/F-12, 15\% (v/v) FBS, 0.525\% (w/v) agar). After the bottom layer was solidified, $1 \mathrm{ml}$ of top agar-medium mixture (DMEM/F-12, 15\% (v/v) FCS, 0.3\% (w/v) agar) containing $5 \times 10^{4}$ cells was added, and the dishes were incubated at $37^{\circ} \mathrm{C}$ for 2 weeks. Plates were stained with $0.01 \%$ Crystal Violet, and then the colonies were counted.

\section{miR-218 Sponge}

Oligos for miR-218 sponge, and scramble construction were constructed using a pcDNA 6.2-GW/ EmGFP-miR plasmid (Invitrogen). MicroRNA SPONGE sequence design was based on previous report [41]. Further multiple copy amplifications were done with recovery of BamH1 and XhoI digested fragments and subcloned into pcDNA 6.2-GW/EmGFP-miR plasmid [3].

\section{In vivo imaging of tumor growth}

All procedures involving animals were conducted in accordance with the institutional animal welfare guidelines of the Chung Shan Medical University. 5-6 weeks old immuno-deficient nude mice (BALB/c nu/ nu mice) were used for the xenograft model. OCSC $\left(1 \times 10^{4}\right.$ cells $\left./ 0.2 \mathrm{~mL} / \mathrm{mouse}\right)$ were injected subcutaneously into the right axilla and the day of cell implantation was designated day 0 . The mice were randomly divided into two groups and fed with either saline (control) or andrographolide $(10 \mathrm{mg} / \mathrm{day} / \mathrm{kg})$ by oral gavage 10 days post implantation. Tumor size measurement was performed using an IVIS50 animal imaging system (Xenogen Corp.). The volume was calculated (according to the following formula: [length $\times$ width $\left.^{2}\right] / 2$ ), and then analyzed by Image-Pro Plus software. Body weight was assessed daily after cell injection. After 20 days, the animals were euthanized, and the primary tumors were weighed and for miR-218/Bmil analysis. 


\section{Statistical analysis}

Statistical Package of Social Sciences software (SPSS; version 13.0) was used for statistical analysis. Student's $t$ test or ANOVA analysis were used to determine statistical significance of the differences between experimental groups; $p$ values less than 0.05 were considered statistically significant.

\section{ACKNOWLEDGMENTS AND FUNDING}

This study was supported by grants from Chung Shan Medical University Hospital (CSH-2014-C-025) and Ministry of Science and Technology (MOST 105-2320-B-182A-004) in Taiwan.

\section{CONFLICTS OF INTEREST}

The authors have declared no conflicts of interest.

\section{REFERENCES}

1. Kamangar F, Dores GM, Anderson WF. Patterns of cancer incidence, mortality, and prevalence across five continents: defining priorities to reduce cancer disparities in different geographic regions of the world. J Clin Oncol. 2006; 24:2137-2150.

2. Chang YC, Jan CI, Peng CY, Lai YC, Hu FW, Yu CC. Activation of microRNA-494-targeting Bmil and ADAM10 by silibinin ablates cancer stemness and predicts favourable prognostic value in head and neck squamous cell carcinomas. Oncotarget. 2015; 6:24002-24016. doi: 10.18632/oncotarget.9057.

3. Yu CC, Tsai LL, Wang ML, Yu CH, Lo WL, Chang YC, Chiou GY, Chou MY, Chiou SH. miR145 targets the SOX9/ ADAM17 axis to inhibit tumor-initiating cells and IL-6mediated paracrine effects in head and neck cancer. Cancer Res. 2013; 73:3425-3440.

4. Chou MY, Hu FW, Yu CH, Yu CC. Sox2 expression involvement in the oncogenicity and radiochemoresistance of oral cancer stem cells. Oral Oncol. 2015; 51:31-39.

5. Prince ME, Sivanandan R, Kaczorowski A, Wolf GT, Kaplan MJ, Dalerba P, Weissman IL, Clarke MF, Ailles LE. Identification of a subpopulation of cells with cancer stem cell properties in head and neck squamous cell carcinoma. Proc Natl Acad Sci USA. 2007; 104:973-978.

6. Chen YS, Wu MJ, Huang CY, Lin SC, Chuang TH, Yu CC, Lo JF. CD133/Src axis mediates tumor initiating property and epithelial-mesenchymal transition of head and neck cancer. PLoS One. 2011; 6:e28053.

7. Clay MR, Tabor M, Owen JH, Carey TE, Bradford CR, Wolf GT, Wicha MS, Prince ME. Single-marker identification of head and neck squamous cell carcinoma cancer stem cells with aldehyde dehydrogenase. Head Neck. 2010; 32:1195-1201.
8. Wu MJ, Jan CI, Tsay YG, Yu YH, Huang CY, Lin SC, Liu CJ, Chen YS, Lo JF, Yu CC. Elimination of head and neck cancer initiating cells through targeting glucose regulated protein78 signaling. Mol Cancer. 2010; 9:283.

9. Yu C, Hu F, Ph DC, Chou M. Targeting CD133 in the enhancement of chemosensitivity in oral squamous cell carcinomas-derived side population cancer stem cells. Head Neck. 2014.

10. Sun S, Wang Z. Head neck squamous cell carcinoma c-Met $(+)$ cells display cancer stem cell properties and are responsible for cisplatin-resistance and metastasis. Int $\mathrm{J}$ Cancer. 2011; 129:2337-2348.

11. Negi AS, Kumar JK, Luqman S, Shanker K, Gupta MM, Khanuja SP. Recent advances in plant hepatoprotectives: a chemical and biological profile of some important leads. Med Res Rev. 2008; 28:746-772.

12. Wang LJ, Zhou X, Wang W, Tang F, Qi CL, Yang X, Wu S, Lin YQ, Wang JT, Geng JG. Andrographolide inhibits oral squamous cell carcinogenesis through NF-kappaB inactivation. J Dent Res. 2011; 90:1246-1252.

13. Chen HW, Lin AH, Chu HC, Li CC, Tsai CW, Chao CY, Wang CJ, Lii CK, Liu KL. Inhibition of TNF-alpha-Induced Inflammation by andrographolide via down-regulation of the PI3K/Akt signaling pathway. J Nat Prod. 2011; $74: 2408-2413$.

14. Trivedi NP, Rawal UM, Patel BP. Potency of andrographolide as an antitumor compound in BHC-induced liver damage. Integr Cancer Ther. 2009; 8:177-189.

15. Jiang X, Yu P, Jiang J, Zhang Z, Wang Z, Yang Z, Tian Z, Wright SC, Larrick JW, Wang Y. Synthesis and evaluation of antibacterial activities of andrographolide analogues. Eur J Med Chem. 2009; 44:2936-2943.

16. Lee YC, Lin HH, Hsu CH, Wang CJ, Chiang TA, Chen JH. Inhibitory effects of andrographolide on migration and invasion in human non-small cell lung cancer A549 cells via down-regulation of PI3K/Akt signaling pathway. Eur J Pharmacol. 2010; 632:23-32.

17. Shi MD, Lin HH, Lee YC, Chao JK, Lin RA, Chen JH. Inhibition of cell-cycle progression in human colorectal carcinoma Lovo cells by andrographolide. Chem Biol Interact. 2008; 174:201-210.

18. Pratheeshkumar P, Sheeja K, Kuttan G. Andrographolide induces apoptosis in $\mathrm{B} 16 \mathrm{~F}-10$ melanoma cells by inhibiting NF-kappaB-mediated bcl-2 activation and modulating p53induced caspase-3 gene expression. Immunopharmacol Immunotoxicol. 2012; 34:143-151.

19. Gunn EJ, Williams JT, Huynh DT, Iannotti MJ, Han C, Barrios FJ, Kendall S, Glackin CA, Colby DA, Kirshner J. The natural products parthenolide and andrographolide exhibit anti-cancer stem cell activity in multiple myeloma. Leuk Lymphoma. 2011; 52:1085-1097.

20. Kumar D, Kumar S, Gorain M, Tomar D, Patil HS, Radharani NN, Kumar TV, Patil TV, Thulasiram HV, Kundu GC. Notch1-MAPK Signaling Axis Regulates 
CD133+ Cancer Stem Cell-Mediated Melanoma Growth and Angiogenesis. J Invest Dermatol. 2016.

21. Yu SL, Chen HY, Chang GC, Chen CY, Chen HW, Singh S, Cheng CL, Yu CJ, Lee YC, Chen HS, Su TJ, Chiang CC, $\mathrm{Li} \mathrm{HN}$, et al. MicroRNA signature predicts survival and relapse in lung cancer. Cancer Cell. 2008; 13:48-57.

22. Seike M, Goto A, Okano T, Bowman ED, Schetter AJ, Horikawa I, Mathe EA, Jen J, Yang P, Sugimura H, Gemma A, Kudoh S, Croce CM, et al. MiR-21 is an EGFRregulated anti-apoptotic factor in lung cancer in neversmokers. Proc Natl Acad Sci USA. 2009; 106:12085-12090.

23. Iorio MV, Casalini P, Tagliabue E, Menard S, Croce CM. MicroRNA profiling as a tool to understand prognosis, therapy response and resistance in breast cancer. Eur J Cancer. 2008; 44:2753-2759.

24. Zhu K, Ding H, Wang W, Liao Z, Fu Z, Hong Y, Zhou Y, Zhang CY, Chen X. Tumor-suppressive miR-218-5p inhibits cancer cell proliferation and migration via EGFR in nonsmall cell lung cancer. Oncotarget. 2016; 7:28075-28085. doi: 10.18632/oncotarget.8576.

25. Zhang S, Hong Z, Li Q, Lei J, Huang H, Liu Q. Effect of MicroRNA-218 on the viability, apoptosis and invasion of renal cell carcinoma cells under hypoxia by targeted downregulation of CXCR7 expression. Biomedicine \& pharmacotherapy $=$ Biomed Pharmacother. 2016; 80:213-219.

26. Kumamoto T, Seki N, Mataki H, Mizuno K, Kamikawaji K, Samukawa T, Koshizuka K, Goto Y, Inoue H. Regulation of TPD52 by antitumor microRNA-218 suppresses cancer cell migration and invasion in lung squamous cell carcinoma. Int J Oncol. 2016.

27. Lu YF, Zhang L, Waye MM, Fu WM, Zhang JF. MiR-218 mediates tumorigenesis and metastasis: Perspectives and implications. Exp Cell Res. 2015; 334:173-182.

28. Yu H, Gao G, Jiang L, Guo L, Lin M, Jiao X, Jia W, Huang J. Decreased expression of miR-218 is associated with poor prognosis in patients with colorectal cancer. Int $\mathrm{J}$ Clin Exp Pathol. 2013; 6:2904-2911.

29. Volinia S, Galasso M, Sana ME, Wise TF, Palatini J, Huebner $\mathrm{K}$, Croce $\mathrm{CM}$. Breast cancer signatures for invasiveness and prognosis defined by deep sequencing of microRNA. Proc Natl Acad Sci USA. 2012; 109:3024-3029.

30. White NM, Bao TT, Grigull J, Youssef YM, Girgis A, Diamandis M, Fatoohi E, Metias M, Honey RJ, Stewart R, Pace KT, Bjarnason GA, Yousef GM. miRNA profiling for clear cell renal cell carcinoma: biomarker discovery and identification of potential controls and consequences of miRNA dysregulation. J Urol. 2011; 186:1077-1083.

31. Tu Y, Gao X, Li G, Fu H, Cui D, Liu H, Jin W, Zhang Y. MicroRNA-218 inhibits glioma invasion, migration, proliferation, and cancer stem-like cell self-renewal by targeting the polycomb group gene Bmil. Cancer Res. 2013; 73:6046-6055.

32. Das RK, Anura A, Pal M, Bag S, Majumdar S, Barui A, Chakraborty C, Ray AK, Sengupta S, Paul RR, Chatterjee J. Epithelio-mesenchymal transitional attributes in oral submucous fibrosis. Exp Mol Pathol. 2013; 95:259-269.
33. Visus C, Ito D, Amoscato A, Maciejewska-Franczak M, Abdelsalem A, Dhir R, Shin DM, Donnenberg VS, Whiteside TL, DeLeo AB. Identification of human aldehyde dehydrogenase 1 family member $\mathrm{A} 1$ as a novel CD8+ T-cell-defined tumor antigen in squamous cell carcinoma of the head and neck. Cancer Res. 2007; 67:10538-10545.

34. Chen YC, Chen YW, Hsu HS, Tseng LM, Huang PI, Lu KH, Chen DT, Tai LK, Yung MC, Chang SC, Ku HH, Chiou $\mathrm{SH}$, Lo WL. Aldehyde dehydrogenase 1 is a putative marker for cancer stem cells in head and neck squamous cancer. Biochem Biophys Res Commun. 2009; 385:307-313.

35. Hu FW, Tsai LL, Yu CH, Chen PN, Chou MY, Yu CC. Impairment of tumor-initiating stem-like property and reversal of epithelial-mesenchymal transdifferentiation in head and neck cancer by resveratrol treatment. Mol Nutr Food Res. 2012; 56:1247-1258.

36. Nguyen LV, Vanner R, Dirks P, Eaves CJ. Cancer stem cells: an evolving concept. Nat Rev Cancer. 2012; 12:133-143.

37. Dean M, Fojo T, Bates S. Tumour stem cells and drug resistance. Nat Rev Cancer. 2005; 5:275-284.

38. Liu C, Tang DG. MicroRNA regulation of cancer stem cells. Cancer Res. 2011; 71:5950-5954.

39. Humphries B, Yang C. The microRNA-200 family: small molecules with novel roles in cancer development, progression and therapy. Oncotarget. 2015; 6:6472-98. doi: 10.18632/oncotarget.3052.

40. Ceppi P, Peter ME. MicroRNAs regulate both epithelial-tomesenchymal transition and cancer stem cells. Oncogene. 2014; 33:269-278.

41. Leite KR, Sousa-Canavez JM, Reis ST, Tomiyama AH, Camara-Lopes LH, Sanudo A, Antunes AA, Srougi M. Change in expression of miR-let7c, miR-100, and miR-218 from high grade localized prostate cancer to metastasis. Urol Oncol. 2011; 29:265-269.

42. Chiu KL, Kuo TT, Kuok QY, Lin YS, Hua CH, Lin CY, Su PY, Lai LC, Sher YP. ADAM9 enhances CDCP1 protein expression by suppressing miR-218 for lung tumor metastasis. Sci Rep. 2015; 5:16426.

43. Xia H, Yan Y, Hu M, Wang Y, Dai Y, Chen J, Di G, Chen X, Jiang X. MiR-218 sensitizes glioma cells to apoptosis and inhibits tumorigenicity by regulating ECOP-mediated suppression of NF-kappaB activity. Neuro Oncol. 2013; 15:413-422.

44. Gao C, Zhang Z, Liu W, Xiao S, Gu W, Lu H. Reduced microRNA-218 expression is associated with high nuclear factor kappa B activation in gastric cancer. Cancer. 2010; 116:41-49.

45. Song L, Huang Q, Chen K, Liu L, Lin C, Dai T, Yu C, Wu Z, Li J. miR-218 inhibits the invasive ability of glioma cells by direct downregulation of IKK-beta. Biochemical and Biochem Biophys Res Commun. 2010; 402:135-140.

46. Kinoshita T, Hanazawa T, Nohata N, Kikkawa N, Enokida H, Yoshino H, Yamasaki T, Hidaka H, Nakagawa M, Okamoto Y, Seki N. Tumor suppressive microRNA-218 
inhibits cancer cell migration and invasion through targeting laminin-332 in head and neck squamous cell carcinoma. Oncotarget. 2012; 3:1386-1400. doi: 10.18632/ oncotarget.709.

47. Yamasaki T, Seki N, Yoshino H, Itesako T, Hidaka H, Yamada Y, Tatarano S, Yonezawa T, Kinoshita T, Nakagawa M, Enokida H. MicroRNA-218 inhibits cell migration and invasion in renal cell carcinoma through targeting caveolin-2 involved in focal adhesion pathway. J Urol. 2013; 190:1059-1068.

48. Park IK, Morrison SJ, Clarke MF. Bmi1, stem cells, and senescence regulation. J Clin Invest. 2004; 113:175-179.

49. Cao L, Bombard J, Cintron K, Sheedy J, Weetall ML, Davis TW. BMI1 as a novel target for drug discovery in cancer. J Cell Biochem. 2011; 112:2729-2741.

50. Ye X, Weinberg RA. Epithelial-Mesenchymal Plasticity: A Central Regulator of Cancer Progression. Trends Cell Biol. 2015.

51. Yang MH, Hsu DS, Wang HW, Wang HJ, Lan HY, Yang WH, Huang CH, Kao SY, Tzeng CH, Tai SK, Chang SY, Lee OK, Wu KJ. Bmil is essential in Twist1induced epithelial-mesenchymal transition. Nat Cell Biol. 2010; 12:982-992.

52. Wu Z, Min L, Chen D, Hao D, Duan Y, Qiu G, Wang Y. Overexpression of BMI-1 promotes cell growth and resistance to cisplatin treatment in osteosarcoma. PLoS One. 2011; 6:e14648.

53. Siddique HR, Saleem M. Role of BMI1, a stem cell factor, in cancer recurrence and chemoresistance: preclinical and clinical evidences. Stem Cells. 2012; 30:372-378.

54. Crea F, Duhagon Serrat MA, Hurt EM, Thomas SB, Danesi R, Farrar WL. BMI1 silencing enhances docetaxel activity and impairs antioxidant response in prostate cancer. Int J Cancer. 2011; 128:1946-1954.
55. Wang E, Bhattacharyya S, Szabolcs A, Rodriguez-Aguayo C, Jennings NB, Lopez-Berestein G, Mukherjee P, Sood AK, Bhattacharya R. Enhancing chemotherapy response with Bmi-1 silencing in ovarian cancer. PLoS One. 2011; 6:e17918.

56. Qin L, Zhang X, Zhang L, Feng Y, Weng GX, Li MZ, Kong QL, Qian CN, Zeng YX, Zeng MS, Liao DF, Song LB. Downregulation of BMI-1 enhances 5-fluorouracil-induced apoptosis in nasopharyngeal carcinoma cells. Biochem Biophys Res Commun. 2008; 371:531-535.

57. Zhang C, Qiu X. Andrographolide radiosensitizes human ovarian cancer SKOV3 xenografts due to an enhanced apoptosis and autophagy. Tumour Biol. 2015; 36:8359-8365.

58. Wang ZM, Kang YH, Yang X, Wang JF, Zhang Q, Yang BX, Zhao KL, Xu LP, Yang LP, Ma JX, Huang GH, Cai J, Sun XC. Andrographolide radiosensitizes human esophageal cancer cell line ECA109 to radiation in vitro. Dis Esophagus. 2016; 29:54-61.

59. Hung SK, Hung LC, Kuo CD, Lee KY, Lee MS, Lin HY, Chen YJ, Fu SL. Andrographolide sensitizes Ras-transformed cells to radiation in vitro and in vivo. $\mathrm{J}$ Radiat Oncol Biol Phys. 2010; 77:1232-1239.

60. Lo WL, Yu CC, Chiou GY, Chen YW, Huang PI, Chien CS, Tseng LM, Chu PY, Lu KH, Chang KW, Kao SY, Chiou SH. MicroRNA-200c attenuates tumour growth and metastasis of presumptive head and neck squamous cell carcinoma stem cells. J Pathol. 2011; 223:482-495.

61. Yu CC, Chen YW, Chiou GY, Tsai LL, Huang PI, Chang CY, Tseng LM, Chiou SH, Yen SH, Chou MY, Chu PY, Lo WL. MicroRNA let-7a represses chemoresistance and tumourigenicity in head and neck cancer via stem-like properties ablation. Oral Oncol. 2011; 47:202-210. 